\title{
Job Satisfaction and its determinants of Public Health Midwives: Sri Lankan experience
}

\author{
Arjuna Thilakarathna \\ Teaching Hospital, Peradeniya. Sri Lanka
}

\begin{abstract}
Job satisfaction is the level of favorableness with which employees view their work. Satisfied work force with their job will influence the countries' productivity and ultimately overall development. Hence the job satisfaction of Public Health Midwives (PHMs) would be an important factor to consider with regard to the quality of service provided by them to the health sector of the country. Therefore the purpose of the current study was to describe the job satisfaction and factors associated with job satisfaction among Public Health Midwives in Kandy District of Sri Lanka.
\end{abstract}

This is a descriptive cross sectional study and the present study was conducted among all PHMs $(n=480)$ who have worked for more than one year in the field of Kandy district. PHMs, who were under the administration of estate and the municipality and those who had less than one year of service in the field work were not included for the study. A self-administered questionnaire was used in the study to gather information. A questionnaire constructed based on two factor theory was selected as the study instrument. The final questionnaire consisted of 13 items which represent motivator or satisfactory variables and the hygienic or dissatisfactory variables.

The percentage of midwives who were satisfied with their job from the study population was $138(28.7 \%)$. Almost half of the population $264(55.1 \%)$ was neither satisfied nor dissatisfied and $78(16.2 \%)$ of midwives were dissatisfied. No one scored as strongly dissatisfied. Median for total satisfactory variables was 7 (mean-6.214) and dissatisfactory variables was 4 (mean- 4.05). Final job satisfaction rated a median of twelve (mean-10.245).

Since satisfactory variables rated more than dissatisfactory variables, it could be concluded that total satisfaction was more influenced by satisfiers (motivators) than dissatisfactory (hygienic factors) variables. Considering the results the author recommends improvement of motivational factors to increase the level of the job satisfaction of the workforce.

Key words - Determinants, Health, Public Health Midwives, Sri Lanka

\section{INTRODUCTION}

$\mathrm{H}$ ealth care system in Sri Lanka consists of well-developed sectors which include primary health care, curative health care, and rehabilitative health care [1]. The delivery of health services is based on an integrated approach through a network of institutional and primary health care units. The midwifery system came into action in Sri Lanka in 1926 at Kalutara district in the Western province. It brought the era to go beyond the four walls of the hospital and commence a service to the mother, infant and children in the community. After 1926, training of public health midwives was started and gradually the number of midwives expanded. At present there are 5676 public health midwives in Sri Lanka (up to 2016).

These Public Health Midwives are attached to Medical Officer of Health(MOH) areas and the numbers are decided according to the population of the $\mathrm{MOH}$ area. Each public health midwife has a defined area of responsibility, with a population ranging from 2000 to 4000 .

Public Health Midwives, who are in direct contact with the client, family and community, have a considerable opportunity to influence the health of the community. When more and more midwives joined the health service in Sri Lanka, their contribution to the achievement of the targets of family health became unprecedented. Midwife has been accepted by the community, as an important category of health personal with the necessary knowledge and skills to benefit the community's health.

With this system in place, health indices of Sri Lanka became comparable to that of developed countries. Maternal mortality ratio has shown a sharp decline over the recent years and is 25.7 per 100, 000 live births in 2015. More than $96 \%$ of deliveries are institutional and infant mortality rate is 8.5 per 1000 live births [2]. Further, Sri Lanka has the highest rates of immunization coverage in the South East Asia region. The corner stone for such a picture is the efficient contribution of midwives in this perspective. As the country has achieved these satisfactory indices in maternal and child health care services, ongoing evaluation system is necessary to sustain such a high standard.

Direct correlation has been identified between health care staff satisfaction and patient satisfaction by recent studies [3]. One of a major cause of staff turnover is low job satisfaction among health care teams [4]. Poor quality of service, lack of organizational commitment, staff shortages and psychosocial stress can be associated with law job satisfaction [5].In the health care sector, only few organizations have made job satisfaction a top priority. Further job satisfaction of work force will influence the country productivity and ultimately, overall development. Hence the job satisfaction of Public Health Midwives (PHM) would be an important factor to consider with regard to the quality of services provided by them.

In the Sri Lankan health care sector, only a few studies have been done on PHMs' job satisfaction.It is essential to identify PHMS' level of job satisfaction and its correlates, so as to 
address those aspects with clarity and to improve their quality of services. Therefore the objective of the current study was to describe the job satisfaction and factors associated with job satisfaction among Public Health Midwives in Kandy District of Sri Lanka.

\section{METHODOLOGY}

A community based descriptive cross sectional study was conducted in Kandy district, the largest health administrative district in the Central province of Sri Lanka. Kandy district having a population of about 1.52 million people of different socio demographic variations has been subdivided into 23 $\mathrm{MOH}$ areas. The present study was conducted among all PHMs $(n=480)$ who have worked for more than a year in any of the $23 \mathrm{MOH}$ areas in Kandy district. PHMs, who were under the administration of estate and the municipality and those who had less than one year of service in the field work, were not included for the study.

A self-administered questionnaire was used to assess the level of job satisfaction. Among various job satisfaction theories in the world, the present study utilized the Frederick Herzberg's two factor theory after extensive literature surveys [6]. Reported studies and other published literatures were perused for this purpose. When selecting this theory cultural acceptability, practicability, suitability to public health care structure in Sri Lanka was taken into consideration.In this two factor theory, Frederick Herzberg states [7] that "job factors could be classified according to whether the factors contribute primarily to satisfaction or to dissatisfaction. First two-factor theory describes that satisfaction and dissatisfaction do not exist on a continuum running from satisfaction through neutral to dissatisfaction. Two dependent continua exist, one running from satisfied to neutral, and another running from dissatisfied to neutral. Second the theory stresses that different job facets influence feeling of satisfaction and dissatisfaction".

A questionnaire which was constructed based on two factor theory was selected as the study instrument [8]. The final questionnaire consisted of 13 items which represent motivator or satisfactory variables and the rest of questionnaire represented hygienic or dissatisfactory variables. Five responses (strongly agree to strongly disagree) were given with each item to be selected by the respondent. Scoring was done as follows. They are "strongly agree" $(+2)$, "agree" $(+1)$, "neither agree nor disagree" $(0)$, "disagree" $(-1)$ and "strongly disagree" (-2). A total score was computed for each respondent by algebraically summing the responses to all the satisfying items and by subtracting from this quantity the algebraic sum of responses to all the dissatisfying items. The maximum and minimum scores that could be obtained by a respondent were therefore +60 and -60 respectively. Final level of job satisfaction was categorized according to the following cut-off levels. They were final score of 60-39 as strongly satisfied (SS), 38-18 as satisfied(S), 17-(-17) as neither satisfied nor dissatisfied (NSND), $-18-(-38)$ as dissatisfied (D) and (-39) to (-60) as strongly dissatisfied.

Job satisfaction scale was developed to ascertain the level of job satisfaction of PHMs in Sri Lankan context since such a scale was not available. Content and consensual validity was obtained by the panel of experts in adopting the questionnaire into Sri Lankan context and also deciding the cut off values. The draft questionnaire was pre-tested among PHMs in a $\mathrm{MOH}$ area in Matale, an administrative district nearby Kandy and the necessary changes were made accordingly. Data was collected by the trained research assistants on the monthly conference days as it is mandatory to all the PHMs to attend this meeting. Those who were absent, the questionnaire was administered on salary days.

All PHMs were educated on purpose of the study before administering the questionnaire. Confidentiality and anonymity of the information was stressed, assured and informed written consent was obtained. Optimal level of personal privacy was provided at the time of answering. Each completed questionnaire was manually checked for completeness before entering the data into the computer. Data analysis was performed using the Statistical Package for Social Science (SPSS) statistical software by the principal investigator. Descriptive statistical methods and Chi square test were used in analysis of data. Administrative clearance was obtained from Regional Director of Health Services (RDHS), Kandy. Ethical clearance was obtained from a local ethics review committee in the region.

\section{RESULTS}

A total of 480 Public Health Midwives participated in the present study. The nonresponse rate was zero.

Table. I: FrequencyDistribution of Public Health Midwives By Demographic And Social Factors

\begin{tabular}{|c|c|c|}
\hline Characteristics & Frequency & Percentage \\
\hline Age category (Years) & & \\
\hline $20-30$ & 32 & 6.6 \\
\hline $31-40$ & 138 & 28.8 \\
\hline $41-50$ & 211 & 44 \\
\hline$>50$ & 99 & 20.6 \\
\hline Marital status & & \\
\hline Unmarried & 75 & 15.6 \\
\hline Married & 405 & 84.4 \\
\hline No of children & & \\
\hline One & 148 & 30.8 \\
\hline Two & 215 & 44.8 \\
\hline Three & 53 & 11 \\
\hline Four & 9 & 1.8 \\
\hline Married but no children & 56 & 11.6 \\
\hline Husband's Employment status & & \\
\hline
\end{tabular}




\begin{tabular}{|c|c|c|}
\hline Unemployed & 164 & 34.1 \\
\hline Employment & 316 & 65.9 \\
\hline Place of residence & & \\
\hline Own home & 297 & 61.8 \\
\hline PHM quarters & 123 & 25.7 \\
\hline Rent home & 37 & 7.8 \\
\hline Relative home & 15 & 3.1 \\
\hline Friend home & 8 & 1.6 \\
\hline Total & 480 & 100 \\
\hline
\end{tabular}

Majority (44\%) of Public Health Midwives are belonging to age group 41-50 years. Minimum age is 24 years and maximum age is 59 years. Mean age is 43.2 years.

Table. II: Frequency Distribution Of Public Health Midwives By Factors Related To Their Occupation

\begin{tabular}{|c|c|c|}
\hline Characteristics & Frequency & Percentage \\
\hline Total experience as PHM & & \\
\hline $0-5$ & 17 & 3.5 \\
\hline $6-10$ & 125 & 26.1 \\
\hline $11-15$ & 103 & 21.4 \\
\hline $16-20$ & 162 & 33.8 \\
\hline $21-25$ & 67 & 14.0 \\
\hline$>26$ & 6 & 1.2 \\
\hline $\begin{array}{c}\text { Experience as PHM in present } \\
\text { station }\end{array}$ & & \\
\hline
\end{tabular}

\begin{tabular}{|c|c|c|}
\hline $0-5$ & 117 & 24.5 \\
\hline $6-10$ & 178 & 37.0 \\
\hline $11-15$ & 97 & 20.2 \\
\hline $16-20$ & 71 & 14.8 \\
\hline $21-25$ & 15 & 3.1 \\
\hline$>26$ & 2 & 0.4 \\
\hline \multicolumn{3}{|c|}{$\begin{array}{l}\text { Distance from place residence } \\
\text { to working field }(\mathrm{km})\end{array}$} \\
\hline$<5$ & 357 & 74.3 \\
\hline $6-10$ & 80 & 16.7 \\
\hline $11-15$ & 20 & 4.3 \\
\hline $16-20$ & 8 & 1.6 \\
\hline $21-25$ & 9 & 1.9 \\
\hline$>26$ & 6 & 1.2 \\
\hline \multicolumn{3}{|l|}{ Availability of PHNS/SPHM } \\
\hline Only PHNS & 164 & 34.2 \\
\hline Only SPHM & 118 & 24.5 \\
\hline Both PHNS and SPHM & 142 & 29.6 \\
\hline None of them & 56 & 11.7 \\
\hline \multicolumn{3}{|l|}{ Population in PHM area } \\
\hline $1000-2000$ & 37 & 7.8 \\
\hline $2001-3000$ & 151 & 31.5 \\
\hline $3001-4000$ & 224 & 46.7 \\
\hline$>4001$ & 67 & 14 \\
\hline Total & 480 & 100 \\
\hline
\end{tabular}

Table. III: Frequency Distribution of Public Heath Midwives According To Descriptive Statistics of Final Level of Satisfaction

\begin{tabular}{|c|c|c|c|c|c|c|c|c|c|c|c|c|c|}
\hline \multirow[t]{3}{*}{ No } & \multirow[t]{3}{*}{ Categories } & \multicolumn{10}{|c|}{ Job satisfaction } & & \\
\hline & & \multicolumn{2}{|c|}{ SS } & \multicolumn{2}{|c|}{$S$} & \multicolumn{2}{|c|}{ NSND } & \multicolumn{2}{|c|}{$\mathrm{D}$} & \multicolumn{2}{|c|}{ SD } & \multicolumn{2}{|c|}{ Total } \\
\hline & & No & $\%$ & No & $\%$ & No & $\%$ & No & $\%$ & No & $\%$ & No & $\%$ \\
\hline 1 & Final level of job satisfaction & 9 & 1.9 & 129 & 26.8 & 264 & 55.1 & 78 & 16.2 & 0 & 0 & 480 & 100 \\
\hline 2 & $\begin{array}{c}\text { Total job satisfaction according } \\
\text { to motivator issues }\end{array}$ & 15 & 3.2 & 213 & 44.3 & 231 & 48.2 & 21 & 4.3 & 0 & 0 & 480 & 100 \\
\hline 3 & $\begin{array}{c}\text { Total job satisfaction according } \\
\text { to hygienic issues }\end{array}$ & 9 & 1.8 & 116 & 24.1 & 323 & 67.3 & 33 & 6.8 & 0 & 0 & 480 & 100 \\
\hline
\end{tabular}

[SS-Strongly Satisfied, S-Satisfied, NSND - Neither Satisfied Nor Dissatisfied, D- Dissatisfied, SD- Strongly Dissatisfied]

The fraction of satisfied midwives with their job from the study population was $138(28.7 \%)$. All most half of the population $264(55.1 \%$ ) was neither satisfied nor dissatisfied and $78(16.2 \%)$ of midwives were dissatisfied. The final job satisfaction of midwives showed normal distribution. $(\mathrm{SD}=10.4$, mean $=13.6, \mathrm{n}=480)$.

Median for total satisfactory variables was 7 (mean-6.214) and dissatisfactory variables was 4 (mean- 4.05). Final job satisfaction rated a median of twelve (mean-10.245
Among the study population $231(48.2 \%)$ has received the score of neither satisfied nor dissatisfied for the questions based on the motivator (satisfiers) factors. However 228 $(47.5 \%)$ had received the score of satisfied or strongly satisfies for the same. Further it was observed that 323 $(67.3 \%)$ of the PHM has express that they are neither satisfied nor dissatisfied with questions reflects the hygienic factors. while $116(24.1 \%)$ satisfied and 33(6.8\%) dissatisfied. 
Table. IV: FrequencyDistribution of Public Heath Midwives Job Satisfaction According To Certain Motivator and Hygienic Factors

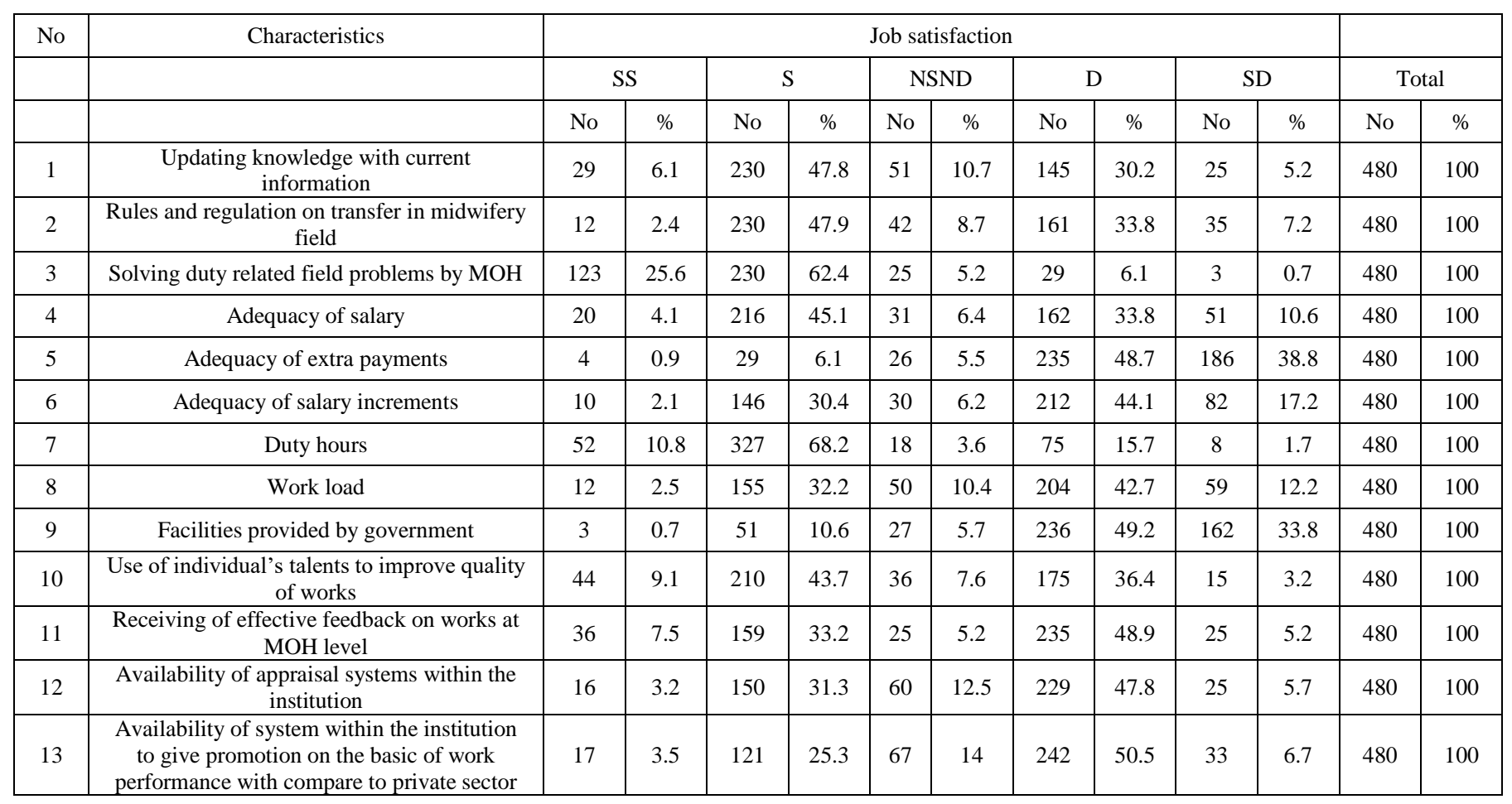

[SS-Strongly Satisfied, S-Satisfied, NSND - Neither Satisfied Nor Dissatisfied, D- Dissatisfied, SD- Strongly Dissatisfied]

Table.V: Frequency Distribution of the Level of Job Satisfaction amongthe Public Health Midwives According To Selected Demographic and Occupational Factors

\begin{tabular}{|c|c|c|c|c|c|c|c|c|c|c|c|c|c|}
\hline \multirow[t]{3}{*}{ No } & \multirow{3}{*}{ Factor } & \multicolumn{10}{|c|}{ Job satisfaction } & & \\
\hline & & \multicolumn{2}{|c|}{ SS } & \multicolumn{2}{|c|}{$\mathrm{S}$} & \multicolumn{2}{|c|}{ NSND } & \multicolumn{2}{|c|}{$\mathrm{D}$} & \multicolumn{2}{|c|}{ SD } & \multicolumn{2}{|c|}{ Total } \\
\hline & & No & $\%$ & No & $\%$ & No & $\%$ & No & $\%$ & No & $\%$ & No & $\%$ \\
\hline \multirow{2}{*}{1} & $<35$ & 0 & 0 & 22 & 27.3 & 32 & 38.6 & 28 & 34.1 & 0 & 0 & 82 & 100 \\
\hline & $36-45$ & 2 & 0.9 & 39 & 18.3 & 162 & 75.6 & 11 & 5.2 & 0 & 0 & 215 & 100 \\
\hline \multirow{3}{*}{2} & $<8$ & 0 & 0 & 20 & 21.5 & 45 & 47.1 & 30 & 31.4 & 0 & 0 & 95 & 100 \\
\hline & $9-16$ & 6 & 3 & 36 & 19 & 125 & 67 & 21 & 11 & 0 & 0 & 187 & 100 \\
\hline & $>17$ & 2 & 0.9 & 58 & 29.2 & 118 & 58.6 & 22 & 11.3 & 0 & 0 & 198 & 100 \\
\hline 3 & Availability of PHNS/ SPHM & & & & & & & & & & & & \\
\hline \multirow[t]{5}{*}{4} & Total population in the field & & & & & & & & & & & & \\
\hline & $1000-2000$ & 0 & 0 & 9 & 25 & 22 & 60 & 6 & 15 & 0 & 0 & 37 & 100 \\
\hline & $2001-3000$ & 2 & 1.2 & 34 & 22.2 & 82 & 54.4 & 34 & 22.2 & 0 & 0 & 151 & 100 \\
\hline & $3001-4000$ & 6 & 2.5 & 60 & 26.7 & 133 & 59.2 & 26 & 11.6 & 0 & 0 & 224 & 100 \\
\hline & $>4001$ & 0 & 0 & 11 & 16.7 & 48 & 72.2 & 7 & 11.1 & 0 & 0 & 68 & 100 \\
\hline
\end{tabular}

[SS-Strongly Satisfied, S-Satisfied, NSND - Neither Satisfied Nor Dissatisfied, D- Dissatisfied, SD- Strongly Dissatisfied] 
majority (75.6\%) of PHMs belonged to the age group of 36 to 45 were neither satisfied nor dissatisfied or satisfied than the age group of PHMs of age less than 36 years $(\mathrm{p}<0.001)$. Further those PHMs with total experience as PHM for 9 years or more were neither satisfied nor dissatisfied or satisfied than

\section{DISCUSSION}

Being a developing country, Sri Lanka has its health indices comparable to that of developed countries. The corner stone for such a picture is the efficient contribution of midwives in this perspective. It is necessary to have an ongoing evaluation system in various aspects to maintain such standard. Hence the job satisfaction of public health midwives would be an important factor to consider with regard to the quality of service provided by them.

In final satisfaction of midwives, median for total satisfactory variables was 7 (mean-6.214) and dissatisfactory variables was 4 (mean- 4.05). Final job satisfaction rated a median of twelve (mean-10.245).Here satisfactory variables rated more than dissatisfactory variables, it could be concluded that total satisfaction was more influenced by satisfiers (motivators) than dissatisfactory (hygienic factors) variables. This observed difference demonstrates that the total satisfaction score is more influenced by the motivation factors (satisfactory variables) than the hygienic factors (dissatisfactory variables). This shows the importance of improving the factors related to motivation of the workforce in order to increase the level of the job satisfaction.

\section{Job Satisfaction in Other Countries}

The level of job satisfaction is high in many countries. Lesser fraction of workers; $4 \%$ in Switzerland, $16 \%$ in Russia and $10 \%$ in the United States of America were reported with low job satisfaction and in the same time Japanese workers got the third lowest among the other countries [9].

However these findings cannot be compared with the present study findings as the geographical differences in the working fields, job functions, work load, system of supervision \& evaluation and also physical infrastructure facilities are quite different to the other countries. Further the above finding was taken not only from the public health workers, with different questionnaires, with different type of scaling systems and in very different socio demographic and in different geographical situation.Therefore we cannot completely compare our study finding with the finding done in other countries.

\section{Job Satisfaction and Socio Demographic Indices}

Two hundred fifteen (44.7\%) of PHMs who are belonging to age category of 36 to 45 years are neither satisfied nor dissatisfied and $31.6 \%$ of PHMs who are older than 46 years and $27.3 \%$ of PHMs who are younger than 35 years are satisfied while $18.3 \%$ of PHMs in the age category of 36-45 are neither satisfied nor dissatisfied(Table V). those who have experience of 8 years or less $p<0.005$ ). Those PHMs who worked with the presence of PHNS and SPHM were reported to be neither satisfied nor dissatisfied or satisfied than those who are working in the absence oftheir immediate supervising officers $(\mathrm{p}<0.05)$.

Herzberg has described this association that" This is a Ushaped function. Initially satisfaction is high, then decreases, and eventually, after hitting a low point, increases again with age". The correlation between age and job satisfaction has been identified in literature as high satisfaction can be achieved when worker get mature (10). In another study, done by Bowen et al [11] found that job satisfaction of university faculty members has been increased with the age and maturity. Further Bowen et al. (1994), Mwange and McCaslin (1994), and Bertz and Judge [11] revealed that direct correlation exist between job satisfaction and years of experience.

When newly trained PHMs appointed to the field they are expecting a transfer or more facility due to poor experience in midwifery and as a result of this PHMs with less experience may not satisfy with a job. When they get experience they may feel that the job is monotonous, no promotion and they may be neither satisfied nor dissatisfied as a PHM. There are different levels of job satisfaction with different total experience as a PHM and this difference is statistically significant $(\mathrm{p}<0.05)$.

\section{Motivator and Hygenic Factors}

Irrespective of availability of PHNS/SPHM or not, the majority are neither satisfied nor dissatisfied as a PHM. But when compare to dissatisfaction, more PHHM are satisfied when PHNS or SPHM are available and observed difference is statistically significant $(p<0.001)$ This is an important finding to highlight that the importance of the immediate supervisors in order to increase the job satisfaction of the PHMM while in turn this could enhance the quality of the service provision. Quality supervision is a prerequisite for effective worker practice. Ideally the MOH office should have both PHNS and SPHM as immediate supervisors of the PHMM.

When supervision is perceived as inadequate or not supportive, workers may be more likely to be dissatisfied [12].In situations where workers did not feel supported by their supervisors, other potentially negative working conditions became more significant [13]. On the other hand, supervisory support was found to be a critical factor in mediating the stress and frustrations of their job. In the present study there is no PHNS or SPHM supervision for $11.7 \%$ of the PHMs. Therefore availability of PHNS or SPHM as immediate supervisor is a very important factor when considering midwifery field. Some researchers have argued that stress does not always have a negative impact on employee job satisfaction [14]. If the employee receives adequate social support, especially support from family 
members (e.g., spouse), the depressive impacts of job stressors can be buffered [15].

Most of PHMs were supplied with PHM quarters, majority are living in their own homes. The reason for this may be the poor quality and poor facilities at those quarters. Also, as majority is living in their field area, they only use their quarters for official work. Ideally PHMs should reside in their field area. Therefore, when appointing a PHM it is better to select them to the area where they are living. This will enhance their work performance, because they would know the area quite well.

Majority of PHMs $(46.7 \%)$ have to serve a total population of 3001 to 4000 and $31.5 \%$ of PHMs serve a total population of 2001 to 3000 . When the total population is high their work load increases in every aspect.

Variables which come under the motivation factors (satisfiers) showed that $241(50.3 \%)$ are satisfied with rules and regulation on transfer in the district while $197(41 \%)$ are not satisfied. Further $236(49.2 \%)$ are satisfied with current salary while $213(44.4 \%)$ are not satisfied. Four hundred and twenty $(87.5 \%)$ are express that their extra payment is not enough and $294(61.3 \%)$ also say their salary increment is not adequate. Several studies done in India have identified that low salaries as a major contributor to dissatisfaction and a frequent precursor to turnover [16].In other studies, however, salary ranks behind other work factors in decisions to stay or leave [22]. In some states, the average salary range in public child welfare is superior to comparable positions in the private sector.

At the same time 379 (79\%) satisfied with current working hour [17]. Two hundred and fifty four $(52.8 \%)$ say that their individual talents are used to improve the quality of services and $260(54.1 \%)$ are not satisfied with $\mathrm{MOH}$ level feedback systems on work. Two hundred and fifty four $(53 \%)$ say that they are not satisfied with existing appraisal system and Majority $275(57.2 \%)$ rated as there is no proper promotion scheme within the midwifery field in comparison to private sector. Opportunity for promotion has been recognized as a major determinant of job satisfaction [18].

Increased responsibility, recognition for accomplishment, challenging work, and achievement has been identified as major factors which contribute to job satisfaction, worker motivation and staff retention [19].All kind of workers including supervisors highly satisfied if they have autonomy to work [20].

\section{V.CONCLUTION}

However, the present study found that younger PHMs were less satisfied with their overall job than older PHMs. Further it concluded that the period of service years and grade in which PHMs belongs to, have a positive impact on the level of overall job satisfaction. Therefore, PHMs who are in early career need supporting programs to improve their job satisfaction as well as to enhance quality of care. The majority of PHMs, who got the appointments for their preference, expressed high level of job satisfaction than others. Therefore, a high degree of transparency and reliability of transfer schemes should be maintained. The majority of PHMs were unhappy with their salary and other payments. Increment of salary and other allowances will not be permitted within the existing salary structure. Therefore, behavioral change and communication programs should be implemented to change their attitudes. Further, system of performance base incentives or salary increment process should be introduced. Majority of PHMs were not satisfied with existing performance appraisal system. A psychometrically sound system of performance appraisal should be deployed to motivate and encourage them. Majority of PHMs were unsatisfied with their facility available within the working environment. Provision of needy facilities (such as office rooms) should be considered. It has to be recommended to appoint both PHNS and SPHM as an immediate supervisor for PHMs. Availability of immediate supervisor has significant influence on job satisfaction [21].

Finallyobserved differences demonstrate that the total satisfaction score is more influenced by the motivation factors (satisfactory variables) than the hygienic factors (dissatisfactory variables). This shows the importance of improving the factors related to motivation of the workforce in order to increase the level of job satisfaction.

\section{REFERENCES}

[1] Master plan, Ministry of health, 2010-2015.

[2] Annual Health Bulletin, Ministry of Health, 2016.

[3] Michael,Marsland,Marsland,Van de Looij, Benders. (1999). Job Satisfaction: Putting Theory into Practice.FamPractManag. 6(9), 26-30.

[4] Shannon L. Wagner \&Melanie O'Neill. (2012). Job, Life, and Relationship Satisfaction for Paid-Professional Fire-fighters. Journal of Loss and Trauma. 17, 423-438

[5] Shader, Karen, Broome, Marion E, Broome, Carroll D. (2001).Factors Influencing Satisfaction and Anticipated Turnover for Nurses in an Academic Medical Center.The Journal of Nursing Administration,31(4),210-216

[6] Michael R. Carrell and Norbert F. Elbert. (1974). Some Personal and Organizational Determinants of Job Satisfaction of Postal Clerks. Academy of Management Journal. 16, 368-373.

[7] Herzberg, F.I. (1987).One more time: How do you motivate employees?. Harvard Business Review. 65(5), 109-120.

[8] Agho AE, Muller CW, Price JL.1993. Determinants of employee job satisfaction: An empirical test of a causal model. Human Relation. 46,1007-1028.

[9] Cabrita, perista, (2006). Nurses job satisfaction-A longitudinal analysis Research in Nursing \& Health. 10,227-237

[10] Gibson, Klein. (1970).Employee Attitudes as a Function of Age and Length of Service.Academy of Management Journal. 13( 4), 115-119

[11] Bowen, B. E., \&Radhakrishna, R. B. (1991). Job satisfaction of agricultural education faculty: A constant phenomena. Journal of Agricultural Education. 32 (2), 16-22.

[12] Rycraft, J. R. (1994).The party isn't over: The agency role in the retention of public child welfare caseworkers. Social Work. 39, 75-80.

[13] Conway, P. G., Williams, M. S., \& Green, J. L. (1987). A model of job facet satisfaction. Journal of Social Work Education, 23, 48-57.

[14] Agho, A. O., Price, J. L., \& Mueller, C. W. (1992). Discriminant validity of measures of job satisfaction, positive affectivity and 
negative affectivity. Journal of Occupational and Organizational Psychology. 65, 185-19.

[15] Barnett, Donald E. A. (2008). Quantitative Examination of the Predictive Relationship between Leadership and Job Satisfaction. International Journal of Research in Education and Science. 4 (1).226-236

[16] Jayaratne, S., \& Chess, W. A. (1984). Job satisfaction, burnout, and turnover: A national study. Social Work. 29,448-453.

[17] Alison L. Booth, Jan C. Van Ours. 92008).Job Satisfaction and Family Happiness: The Part-Time Work Puzzle.The Economic Journal. 118(526), 77-99.

[18] Jayaratne, S., \& Chess, W. A. (1985). Factors associated with job satisfaction and turnover among child welfare workers. A handbook of child welfare, 760-766).
[19] Morton, D. R. (1992). Adjunct faculty embraced: The institution's responsibility. Christian Education Journal. 9(2), 398-407.

[20] Joan Arches. (1991).Social Structure, Burnout, and Job Satisfaction.Social Work. 36 (3),202-206.

[21] Yoder, L.H. (1995).Staff nurses' career development relationships and self-reports of professionalism. Job satisfaction and intent to stay. Nursing Research. 44,290-297.

[22] Alberta J,Elletta,JacquelynI,EllisaTonyaM,Westbrook, Denise,'Dewsc. (2007).A qualitative study of 369 child welfare professionals' perspectives about factors contributing to employee retention and turnover.Children and Youth Services Review. 29(2),264-281 